\title{
The Roll of NaPSS Surfactant on the Ceria Nanoparticles Embedding in Polypyrrole Films
}

\author{
Simona Popescu, Mihaela Mîndroiu, Daniela Cabuzu, and Cristian Pîrvu
}

University Politehnica of Bucharest, 313 Splaiul Independentei, Sector 6, 060042 Bucharest, Romania

Correspondence should be addressed to Cristian Pîrvu; c_pirvu@chim.upb.ro

Received 27 October 2015; Revised 8 April 2016; Accepted 14 April 2016

Academic Editor: Paulo Cesar Morais

Copyright ( 2016 Simona Popescu et al. This is an open access article distributed under the Creative Commons Attribution License, which permits unrestricted use, distribution, and reproduction in any medium, provided the original work is properly cited.

Cerium oxide nanoparticles $\left(\mathrm{CeO}_{2} \mathrm{NPs}\right)$ in crystalline form have been synthesized by a coprecipitation method. CeO $\mathrm{C}_{2}$ nanoparticles were then embedded in polypyrrole (PPy) films during the electropolymerization of pyrrole (Py) on titanium substrate. The influence of poly(sodium 4-styrenesulfonate) (NaPSS) surfactant used during polymerization on the embedding of $\mathrm{CeO}_{2} \mathrm{NPs}$ in polypyrrole films was investigated. The new films were characterized in terms of surface analysis, wettability, electrochemical behaviour, and antibacterial effect. The surface and electrochemical characterization revealed the role of surfactant on PPy doping process cerium oxide incorporation. In the presence of surfactant, $\mathrm{CeO}_{2} \mathrm{NPs}$ are preferentially embedded in the polymeric film while, without surfactant, the ceria nanoparticles are quasiuniformly spread as agglomerates onto polymeric films. The antibacterial effect of studied PPy films was substantially improved in the presence of cerium oxide and depends by the polymerization conditions.

\section{Introduction}

Nowadays, titanium still represents a solution for the choice of base-implant materials in orthopedic and dental field, due to its excellent properties that refers to corrosion resistance and mechanical properties. Many studies have confirmed the necessity of titanium implants pretreatments, in order to accelerate the process of its integration within the surrounding tissue, by designing a new titanium-based material with a bioactive surface [1-5]. The novelty in this domain came always from the ingenuity of methods that have developed in a dynamic way.

Among the variety of methods used to modify the titanium surface in a "friendly" way, the deposition of an adherent, biocompatible, polymer film on titanium represents a simple and efficient alternative [6-10]. In this way, the reactivity of polymer surface could be further implied in the process of biologically active molecules grafting [11, 12]. Another advantage is related to protection of the metal against corrosion and avoiding the problem of ions release in the surrounding tissue $[13,14]$. Moreover, these polymers have the doping ability with different molecules, during their polymerization, thus improving the surface properties for appropriate application [15-17]. The choice of polypyrrole (PPy) as conducting polymer for metallic substrate coating is based on its simple electrochemical polymerization directly onto metallic substrates $[18,19]$. Other important properties, such as high electronic conductivity, good stability regarding the resistance against corrosion in aqueous solution, and good biocompatibility with respect to several cells types in vitro and in vivo, were also highlighted in literature [20-23].

Besides aspects related to biocompatibility, a major importance was focused on antibacterial activity, since the ever-increasing resistance of pathogens towards antibiotics represents major postimplantation problems. Bacteria are able to adapt rapidly to new unfavorable environmental conditions; hence, their resistance to antimicrobial molecules increased substantially. Considering this issues, in the last years the metal oxide nanoparticles have gained attention in developing of new drug delivery systems and antibacterial agents [24-26]. Metal oxide NPs are an important class of inorganic compounds due to their special properties in different domains: optical, magnetic, electronic properties and medicine. Among them, cerium oxide $\left(\mathrm{CeO}_{2}\right)$ became more 
and more utilized as antioxidant, providing an efficient protection against free radicals and as antimicrobial agent [27-29]. The small size of particles allows the interaction with biological entities (proteins, DNA molecules, and membranes).

In this respect, as a polymeric matrix, PPy has been already subjected to incorporation of different antibacterial substances such as silver nanoparticles [30, 31] biodegradable compounds such as dextrin or chitosan [32,33], PEG [34], or other carotenoid compounds like torularhodin [35].

The idea of combining a polymer with nanoparticles to create a composite material represents a promising alternative since these materials combine both the unique properties of nanoparticles with those of the polymer, resulting in a new material with specific properties. The incorporation of ceria particles in polypyrrole film requires some special precautions. These particles are stabilized by electrostatics forces and are extremely sensitive to perturbations of $\mathrm{pH}$, ionic strength, and concentration that may dramatically modify their thermodynamic stability. The low stability occurs due to high surface-to-volume ratio for particles and from the strong reactivity of the surface chemical sites to physicochemical changes. Therefore, for some applications, the challenge is to find appropriate conditions to prepare $\mathrm{CeO}_{2}$ polymeric composite in which ceria nanoparticles are dispersed homogeneously in a polymer matrix [36].

Literature contains one study about the incorporation of $\mathrm{CeO}_{2}$ in dodecyl sulfate doped polypyrrole films (PPyDS) deposited on gold electrode. It was concluded that $\mathrm{CeO}_{2}$ NPs have the ability to modify the morphology of electrodeposited PPy-DS thin films, but without highlighting the film morphology and the influence of the surfactant on ceria nanoparticles distribution into the polymeric film [37].

In the present study, poly(sodium 4-styrenesulfonate) (NaPSS) was selected as surfactant based on previous studies $[38,39]$ and it is expected to provide a good $\mathrm{CeO}_{2}$ distribution and a better embedding in the polymer nanocomposite film deposited on titanium surface. Two $\mathrm{PPy}-\mathrm{CeO}_{2}$ composite films obtained with and without NaPSS were studied comparatively, in terms of surface properties, electrochemical stability, and antibacterial activity.

\section{Experimental Part}

2.1. Synthesis of $\mathrm{CeO}_{2}$ Nanoparticles. For the synthesis of $\mathrm{CeO}_{2}$ nanoparticles we applied a simple hydroxide mediated approach that uses cerium nitrate hexahydrate $\left(\mathrm{Ce}\left(\mathrm{NO}_{3}\right)_{3} \cdot 6 \mathrm{H}_{2} \mathrm{O}>99.5 \%\right.$; Aldrich Chemicals, USA $)$ as starting material and sodium hydroxide as precipitating agent. All the chemical reagents were used without purification.

The starting solutions were $0.1 \mathrm{M} \mathrm{Ce}\left(\mathrm{NO}_{3}\right)_{3} \cdot 6 \mathrm{H}_{2} \mathrm{O}$ and $0.3 \mathrm{M} \mathrm{NaOH}$, prepared with double distilled water. First step consists in adding dropwise the $\mathrm{NaOH}$ solution for 3 hours, under continuous stirring at room temperature until a pinkish precipitate is obtained. The vigorous stirring is very important because it influences the product particle size and its distribution.

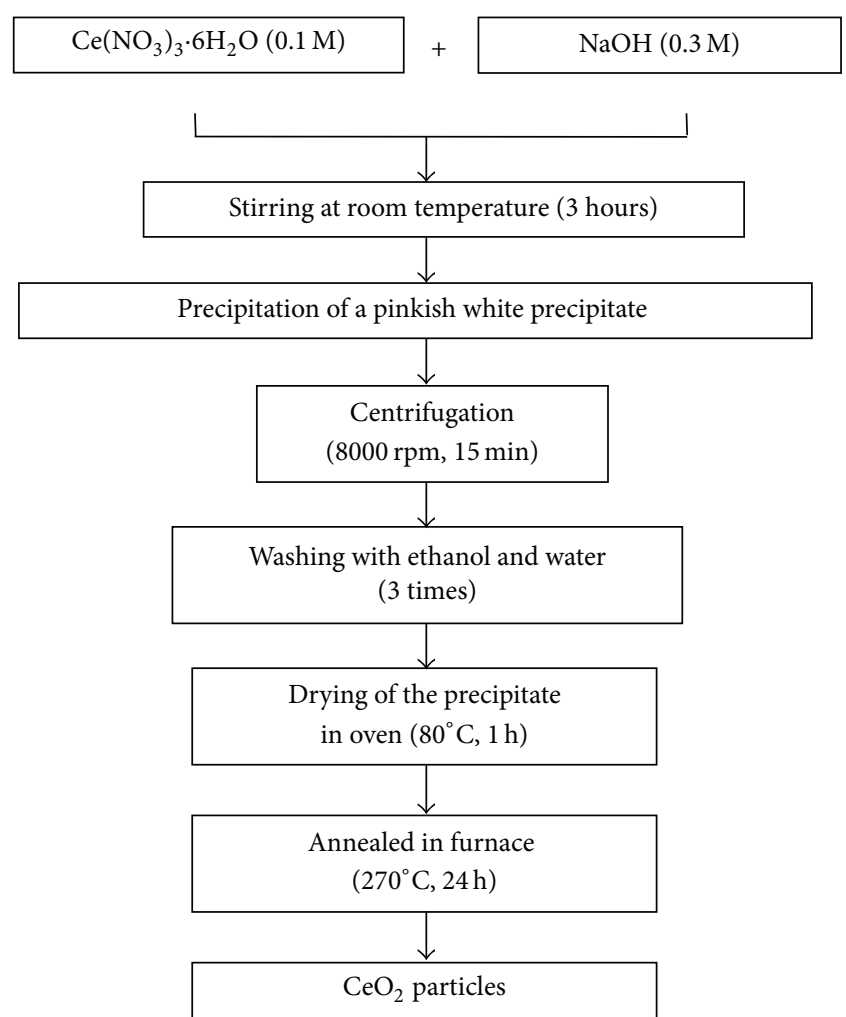

Figure 1: Synthesis of $\mathrm{CeO}_{2}$ nanoparticles.

The apparition of a pinkish precipitate suggests the oxidation of $\mathrm{Ce}(\mathrm{OH})_{3}$ into $\mathrm{Ce}(\mathrm{OH})_{4}$ that occurs in the presence of dissolved oxygen, while the $\mathrm{pH}$ was maintained around 9. Finally, it became a light yellow suspension, characteristic for $\mathrm{CeO}_{2}$.

The reactions during the synthesis are the following:

$$
\begin{aligned}
& \mathrm{Ce}\left(\mathrm{NO}_{3}\right)_{3} \cdot 6 \mathrm{H}_{2} \mathrm{O}_{(\mathrm{s})} \longrightarrow \mathrm{Ce}_{(\mathrm{aq})}^{3+}+3 \mathrm{NO}_{3(\mathrm{aq})}^{-}+6 \mathrm{H}_{2} \mathrm{O} \\
& 2 \mathrm{Ce}_{(\mathrm{aq})}^{3+}+\frac{1}{2} \mathrm{O}_{2}+6 \mathrm{OH}^{-} \stackrel{\mathrm{pH} \approx 9}{\longrightarrow} 2 \mathrm{CeO}_{2}+3 \mathrm{H}_{2} \mathrm{O}
\end{aligned}
$$

In another step, the yellow precipitate was centrifuged three times, washed well with ethanol and distilled $\mathrm{H}_{2} \mathrm{O}$ three times, and then dried in an oven at $80^{\circ} \mathrm{C}$ for 1 hour, followed by an annealing process at $270^{\circ} \mathrm{C}$ for $24 \mathrm{~h}$. The resulting precipitate is a light yellow precipitate that was further analyzed through XRD. Figure 1 presents the schematic diagram for $\mathrm{CeO}_{2}$ particles synthesis.

\subsection{Preparation of Titanium Substrate before Polymer Films Electrodeposition. Commercially pure $\mathrm{Ti}$ discs of $10 \mathrm{~mm}$ diameter and $1 \mathrm{~mm}$ thickness (99.6\% purity, grade 2, Good- fellow Cambridge Ltd., UK) were used. The surface of test specimens was polished with $\mathrm{SiC}$ paper to grade 4000 and then washed with a large amount of water followed by acetone and finally rinsed with distilled water and dried in air at room temperature.}

2.3. Synthesis of PPy Films and $\mathrm{PPy}-\mathrm{Ce} \mathrm{O}_{2}$ with and without Surfactant. Synthesis of polymeric films was performed by 
potentiodynamic polymerization method. Polypyrrole films were electrodeposited on titanium substrate (Ti/PPy) from an aqueous solution containing freshly distilled pyrrole (Py $0.4 \mathrm{~mol} \cdot \mathrm{dm}^{-3}$ purchased from Merck, purity > 98\%) and oxalic acid $\left(0.2 \mathrm{~mol} \cdot \mathrm{dm}^{-3}\right)$ as support electrolyte. Nanocomposite films were obtained by adding cerium oxide nanoparticles $\left(\mathrm{CeO}_{2} \mathrm{NPs}, 40 \mu \mathrm{g} \cdot \mathrm{mL}^{-1}\right)$ in the electrolytic solution (Ti/PPy-CeO $\mathrm{Ce}_{2} \mathrm{NPs}$ ). $\mathrm{CeO}_{2} \mathrm{NPs}$ were ultrasonically dispersed prior to the proper electrosynthesis step. In order to modify the surface characteristics of the polymer films, NaPSS $\left(0.1 \mathrm{~mol} \cdot \mathrm{dm}^{-3}\right)$ was added in the polymerization solution (Ti/PPy-NaPSS). The optimal surfactant concentration was established in a previous work [38]. The surfactant was also introduced along with $\mathrm{CeO}_{2} \mathrm{NPs}$ in the composition of polymerization solution to study its influence on nanoparticles incorporation in the polymeric films (Ti/PPy-NaPSS-CeO NPs). All solutions were prepared using ultra-pure deionized Milli-Q water.

The films electrosynthesis was carried out using one compartment cell with three electrodes: titanium as working electrode, platinum counter electrode and $\mathrm{Ag} / \mathrm{AgCl}$, and $\mathrm{KCl}$ reference electrode, connected to an Autolab PGSTAT $302 \mathrm{~N}$ potentiostat with general-purpose electrochemical system software. Polymerization was performed by applying 5 consecutive cyclic voltammetric scans between 0 and $0.95 \mathrm{~V}$ versus $\mathrm{Ag} / \mathrm{AgCl}$ using a $50 \mathrm{mV} \cdot \mathrm{s}^{-1}$ scan rate.

\subsection{Methods for Polymer Nanocomposite Coatings Characterization}

2.4.1. Surface Characterization. Scanning electron microscopy (SEM) images were taking with FEI Nova NanoSEM 630 FEG-SEM (SEM with Field Emission Gun) with ultra-high resolution characterization at high and low voltage in high vacuum. The voltage of SEM analysis was $20 \mathrm{kV}$ and the magnification of the images was between 1000x and 50000x. The elemental composition was investigated using Carl Zeiss Evo 50 XVP scanning electron microscope (SEM) equipped with energy dispersive X-ray analysis (EDAX) Quantax Bruker 200 accessory.

$\mathrm{X}$-ray diffraction (XRD): the crystalline nature of $\mathrm{CeO}_{2}$ particles was analyzed using a Rigaku Ultima IV X-ray diffractometer in Bragg Brentano parafocusing setup with high resolution, using $\mathrm{CuK} \alpha$ radiation $(\lambda=0.154 \mathrm{~nm})$. The source was operated at $40 \mathrm{kV}$ and $40 \mathrm{~mA}$.

The contact angle of a drop of water with the films surface was measured with a Contact Angle Meter-KSV Instruments CAM 100 equipment. The hydrophilic/hydrophobic balance of synthesized films was evaluated by measuring the static contact angle $(\theta)$ of a drop of water deposited on the studied film surface. Each contact angle value is the mean value from 5 measurements. The investigation was carried out at $25^{\circ} \mathrm{C}$.

2.4.2. Electrochemical Characterization. Electrochemical stability evaluation was performed at room temperature, using potentiostatic assembly with a single compartment and three electrodes: working electrode (samples Ti, Ti/PPy, Ti/PPy$\mathrm{CeO}_{2}$ NPs, Ti/PPy-NaPSS, and Ti/PPy-NaPSS-CeO ${ }_{2}$ NPs), a counter electrode (Metrohm Pt disk), and a reference electrode (Metrohm Ag/AgCl, $3 \mathrm{M} \mathrm{KCl}$ ) connected to an Autolab PGSTAT 302N potentiostat/galvanostat. The data were collected with NOVA 1.10 software.

All electrochemical characterizations were made in an aqueous buffer testing solution composed of $\mathrm{NaCl} 8.74 \mathrm{~g} \cdot \mathrm{L}^{-1}$, $\mathrm{NaHCO}_{3} \quad 0.35 \mathrm{~g} \cdot \mathrm{L}^{-1}, \quad \mathrm{Na}_{2} \mathrm{HPO}_{4} \cdot 12 \mathrm{H}_{2} \mathrm{O} \quad 0.06 \mathrm{~g} \cdot \mathrm{L}^{-1}, \quad$ and $\mathrm{NaH}_{2} \mathrm{PO}_{4} 0.06 \mathrm{~g} \cdot \mathrm{L}^{-1}$ at $\mathrm{pH}$ 6.7. The substances were purchased from Sigma-Aldrich Corp. (St. Louis, MO, USA).

Polarization curves were registered at $\pm 200 \mathrm{mV}$ versus $\mathrm{OCP}$, at a scan rate of $2 \mathrm{mV} / \mathrm{s}$ and corrosion parameters were computed based on Tafel plots: $i_{\text {cor }}$ (corrosion current density), $R_{\mathrm{p}}$ (polarization resistance), $E_{\text {cor }}$ (corrosion potential), and $v_{\text {cor }}$ (corrosion rate). For electrochemical experiments the electrode area exposed to the solution was $0.2826 \mathrm{~cm}^{2}$.

Cyclic potentiodynamic polarization was performed starting from $-0.5 \mathrm{~V}$ to $0.5 \mathrm{~V}$, with a scan rate of $100 \mathrm{mV} / \mathrm{s}, 10$ cycles in buffer solution.

The electrochemical impedance spectra (EIS) were acquired in the frequency range of $0.1-10^{5} \mathrm{~Hz}$ in order to obtain Nyquist plots by applying a small excitation amplitude of $10 \mathrm{mV}$.

The Mott-Schottky measurements were made from a start potential of $-0.5 \mathrm{~V}$ to an end potential of $0.5 \mathrm{~V}$ with a step potential of $0.05 \mathrm{~V}$. In this work, a frequency of $10 \mathrm{kHz}$ for Mott-Schottky measurements was applied [40].

2.4.3. Antibacterial Activity Evaluation of Polymer Nanocomposite Coatings. The antibacterial activity of polymer nanocomposite films was tested against human pathogenic microbial strain, Escherichia coli ATCC 8738. The bacterial strains were grown in Luria Bertani Agar (LBA) plates at $37^{\circ} \mathrm{C}$ with the following composition: peptone (Merck), $10 \mathrm{~g} \cdot \mathrm{L}^{-1}$; yeast extract (Biolife) $5 \mathrm{~g} \cdot \mathrm{L}^{-1}, \mathrm{NaCl}$ (Sigma-Aldrich) $5 \mathrm{~g} \cdot \mathrm{L}^{-1}$, and agar (Fluka) $20 \mathrm{~g} \cdot \mathrm{L}^{-1}$.

The stock culture was maintained at $4^{\circ} \mathrm{C}$. All aqueous solutions were prepared with deionized water. To exploit antibacterial potential of the samples Kirby-Bauer diskdiffusion method was performed [41]. In brief, sterile LBA plates were prepared by pouring the sterilized media in sterile Petri plates under aseptic conditions. The bacterial strain, $1 \mathrm{~mL}$, was spread on agar plates and then sterile samples were applied on plate surface. At the end of the incubation time $(24 \mathrm{~h})$, the diameter of microbial growth inhibition halo was measured in millimeters [35].

\section{Results and Discussion}

\subsection{Characterization of $\mathrm{CeO}_{2}$ Nanoparticles Powder}

3.1.1. XRD Characterization. The crystalline nature of $\mathrm{CeO}_{2}$ nanoparticles prepared according to hydroxide mediated approach can be deduced from the X-ray diffraction spectra shown in Figure 2. The XRD pattern of the heat treated powder was registered from 10 to 90 degrees, $2 \theta / \theta$ scan axis, with $0.02^{\circ}$ angular step and $0.5 \mathrm{sec} / \mathrm{step}$. The resulting pattern revealed the formation of well-crystallized single phase material. The chemical synthesized powder exhibits lines that 


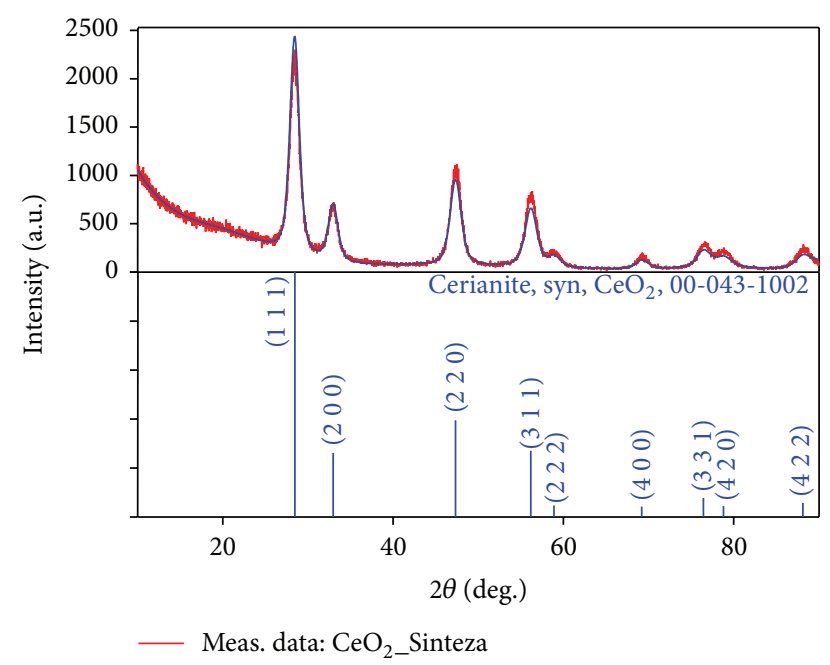

FIgURE 2: XRD diffraction patterns of ceria nanoparticles $\left(\mathrm{CeO}_{2}\right)$.

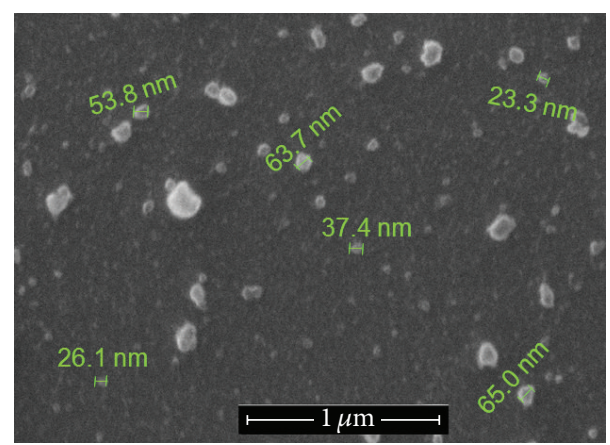

FIGURE 3: SEM image obtained on $\mathrm{CeO}_{2}$ powder prepared by hydroxide mediated approach.

correspond to crystal planes (111), (200), (220), (311), (222), (400), (331), (420), and (422) that are characteristics for $\mathrm{CeO}_{2}$, according to those of centered face cubic (CFC) fluorite structured $\mathrm{CeO}_{2}$ crystal. No extra peaks corresponding to any other secondary phases are observed.

The crystal planes were in accordance with ICDD (PDF2.DAT) $\left(\mathrm{CeO}_{2} /\right.$ Cerianite, syn, DB card number 00-0431002). The diffraction peaks in these $\mathrm{XRD}$ spectra indicate the pure cubic fluorite structure.

3.1.2. SEM Characterization. SEM images of $\mathrm{CeO}_{2}$ powder prepared by hydroxide mediated approach are shown in Figure 3. From the SEM images, it was found that $\mathrm{CeO}_{2}$ particles are characterized by a size of the powder in the range $20-70 \mathrm{~nm}$. Also, there were some visible aggregates formed by particles quite agglomerated.

\subsection{Electrosynthesis of Polypyrrole Nanocomposite Thin Films} on Titanium Electrodes. The CV curves from electrodeposition of PPy films on titanium substrate are presented in Figure 4.

For all samples the current density gradually increases in the successive CV cycles, showing the electrodeposition

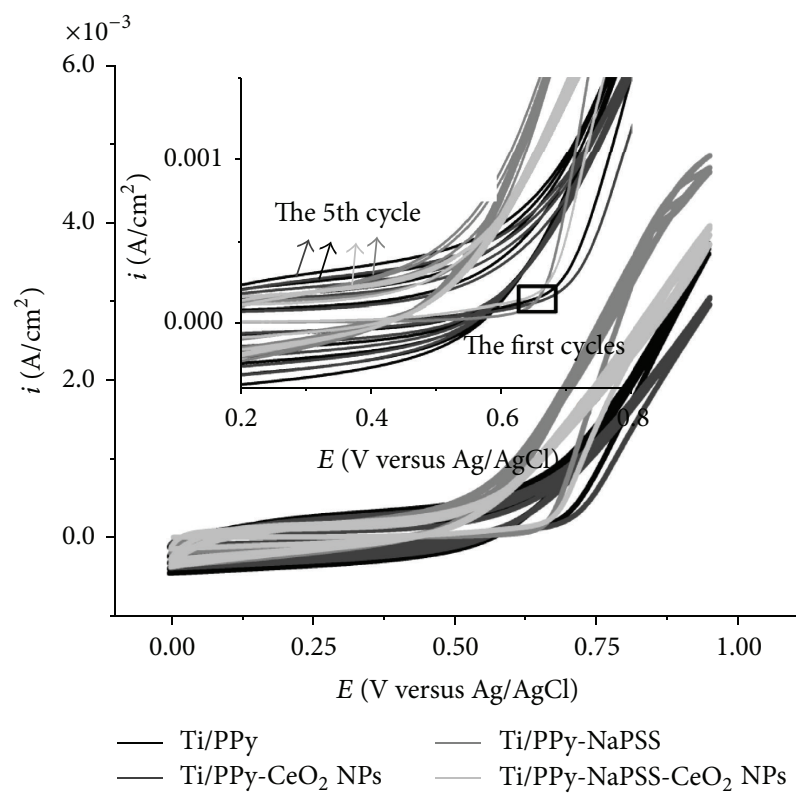

FIgure 4: Cyclic voltammograms of PPy-nanocomposite films electrodeposition on titanium substrate.

of polypyrrole or polypyrrole nanocomposite films onto titanium substrate.

The presence of NaPSS surfactant in the polymerization solution seems to improve Py polymerization rate. The total electric charge used for polymerization is higher in the presence of NaPSS $\left(0.40 \mathrm{C} / \mathrm{cm}^{2}\right)$ comparing to PPy film $\left(0.24 \mathrm{C} / \mathrm{cm}^{2}\right)$, as can be seen from Figure 5. If we consider that the entire charge is used for polymerization process, this can be an indication that the thickness of the polymer film obtained in the presence of surfactant is higher. During the polymerization of pyrrole, $\mathrm{PSS}^{-}$has three different roles: $\mathrm{PSS}^{-}$ (i) stabilizes the radical cation of the pyrrole monomer, (ii) acts as a charge balancing dopant for PPy, and (iii) renders the dispersion of the growing PPy chains in the final polymer film. Small oxalate molecule dopants have a similar doping function; however they did not render the final complex dispersible [42].

By adding $\mathrm{CeO}_{2} \mathrm{NPs}$ in polymerization solution that contains pyrrole monomer and oxalic acid $(\mathrm{pH}=1.4)$, the total charge used for polymerization decreases to $0.20 \mathrm{C} / \mathrm{cm}^{2}$. In this $\mathrm{pH}$ conditions the ceria nanoparticles are positively charged, according to literature [43]. $\mathrm{Py}^{+}$cationic radical stability in the polymerization process was diminished, and thus the electrodeposition rate decreased. Electrostatic repulsions between positive cerium oxide and $\mathrm{PPy}^{+}$could result in pushing positive $\mathrm{CeO}_{2}$ nanoparticles to the surface of polymer film during polymerization, Figure $6(\mathrm{a})$.

Different behaviour can be observed when $\mathrm{CeO}_{2} \mathrm{NPs}$ are added in the pyrrole and NaPSS acid polymerization solution. In the presence of surfactant the surface charge of $\mathrm{CeO}_{2} \mathrm{NPs}$ became negative as a consequence of adsorption of $\mathrm{PSS}^{-}$ anions on their surface [43]. Thus, due to the electrostatic interactions between, in this situation, negatively charged $\mathrm{CeO}_{2}$ nanoparticles and cationic $\mathrm{PPy}^{+}$matrix (doping) the 


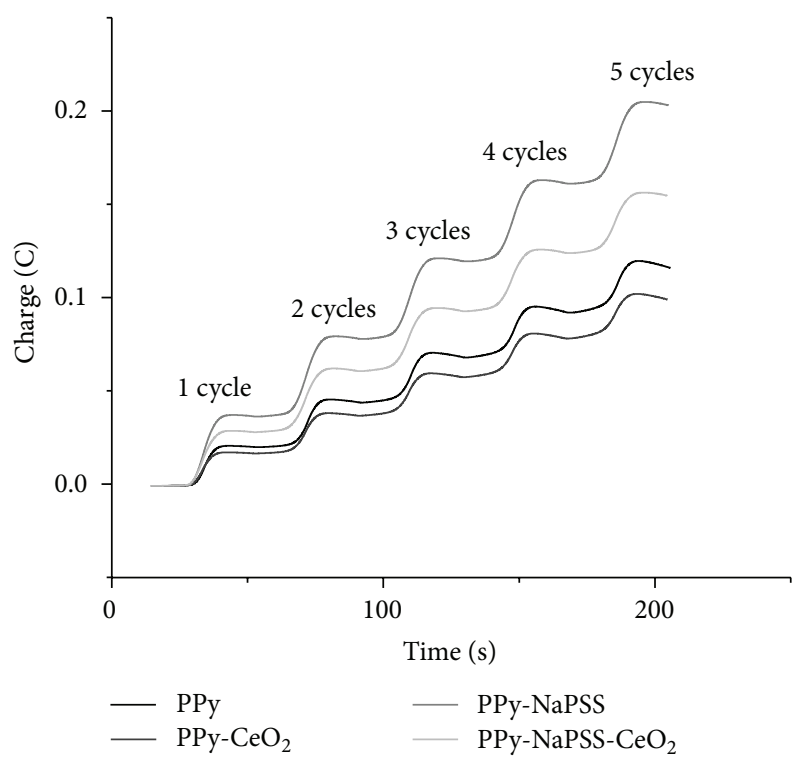

FIGURE 5: Electrical charge evolution with polymerization time for polymer nanocomposite films.

compacting degree of the polymeric film is expected to be improved, Figure 6(b). In this case the total electrical charge used for polymerization decreases from $0.40 \mathrm{C} / \mathrm{cm}^{2}$ to $0.32 \mathrm{C} / \mathrm{cm}^{2}$. The embedding of $\mathrm{CeO}_{2} \mathrm{NPs}$ in PPy matrix starts right from the first cycle when the titanium surface is positively charged by the decrease of the Fermi level due to electrode anodic polarization. Moreover, the negatively charged ceria nanoparticle and PSS $^{-}$could be directly adsorbed on the positively charged titanium surface.

These different interactions between $\mathrm{PPy}^{+}$and positively/negatively charged $\mathrm{CeO}_{2} \mathrm{NPs}$ are intended to bring major changes in terms of morphology, wettability, electrochemical stability, and antibacterial activity of these polymer nanocomposite films.

\subsection{Surface Characterization of PPy-Nanocomposite Films}

3.3.1. SEM and EDAX Analysis. The SEM images corresponding to surface of PPy-CeO 2 NPs and PPy-NaPSS-CeO $\mathrm{NPs}_{2}$ are illustrated in Figure 7. The surface morphology analysis sustains and completes the expected changes in the polymeric films structure, due to the role played by the surfactant on $\mathrm{CeO}_{2}$ NPs embedded in PPy films.

Figure 7 (a) reveals a quasiuniform spreading of $\mathrm{CeO}_{2}$ NPs agglomerates onto polymeric matrix. This confirms the presumed idea, from anterior section, sustaining the nanoparticles pushed from the inside to outside polymer film surface, due to the electrostatic repulsion between positively charged $\mathrm{CeO}_{2}$ NPs and $\mathrm{PPy}^{+}$as was represented in Figure 6(a). $\mathrm{CeO}_{2}$ NPs agglomeration can be associated with (i) suggested electrostatic repulsions towards $\mathrm{PPy}^{+}$, (ii) low stability occurred due to high surface-to-volume ratio, and (iii) strong reactivity of the nanoparticles surface chemical sites. From Figure 7(b) both $\mathrm{CeO}_{2} \mathrm{NPs}$ aggregates of
TABLE 1: EDAX analyzes for PPy film, $\mathrm{PPy}-\mathrm{CeO}_{2}$ NPs film, and PPy$\mathrm{NaPSS}-\mathrm{CeO}_{2}$ NPs film.

\begin{tabular}{lcccccc}
\hline \multirow{2}{*}{ Samples } & \multicolumn{7}{c}{ Element } \\
& $\mathrm{Ti}$ & $\mathrm{C}$ & $\mathrm{N}$ & $\mathrm{O}$ & $\mathrm{Ce}$ & $\mathrm{S}$ \\
& & \multicolumn{7}{c}{ (Atomic\%) } \\
\hline $\mathrm{Ti} / \mathrm{PPy}$ & 50.77 & 21.55 & 9.72 & 15.94 & - & - \\
$\mathrm{Ti} / \mathrm{PPy}_{-} \mathrm{CeO}_{2} \mathrm{NPs}_{\mathrm{N}}$ & 35.97 & 33.5 & 10.64 & 19.16 & 0.33 & - \\
$\mathrm{Ti} / \mathrm{PPy}-\mathrm{NaPSS}_{-} \mathrm{CeO}_{2}$ NPs & 24.07 & 42.32 & 11.4 & 20.42 & 0.32 & 1.28 \\
\hline
\end{tabular}

hundreds nanometers and free nanoparticles with dimension less than $50 \mathrm{~nm}$ can be observed.

Comparatively, in Figure 7(c), the surface morphology of PPy-NaPSS- $\mathrm{CeO}_{2} \mathrm{NPs}$ is presented. $\mathrm{CeO}_{2} \mathrm{NPs}$ aggregates are less numerous than on $\mathrm{PPy}-\mathrm{CeO}_{2} \mathrm{NPs}$ surface and their sizes are also more reduced. The small amount of $\mathrm{CeO}_{2} \mathrm{NPs}$ aggregates on the surface could be an additional argument to the fact that, in the presence of surfactant, negatively charged $\mathrm{CeO}_{2}$ NPs are preferentially embedded in the polymeric film due to the electrostatic interactions with $\mathrm{PPy}^{+}$(doping process) mentioned above. Figure $7(\mathrm{~d})$ shows $\mathrm{CeO}_{2} \mathrm{NPs}$ aggregates with dimensions comprised between $150 \mathrm{~nm}$ and $300 \mathrm{~nm}$ and the amount of nonassociated nanoparticles between $50 \mathrm{~nm}$ and $80 \mathrm{~nm}$ seems to be greater.

Moreover, the most important information highlighted by EDAX analysis consists in proving of $\mathrm{CeO}_{2} \mathrm{NPs}$ presence on/into the polymer film. Furthermore, the cerium amount is almost the same, about 0.32 at \%, for both $\mathrm{PPy}-\mathrm{CeO}_{2}$ NPs and PPy-NaPSS- $\mathrm{CeO}_{2}$ NPs film (Table 1). This means that almost the same quantity of $\mathrm{CeO}_{2} \mathrm{NPs}$ is differently distributed: mainly on PPy surface for $\mathrm{PPy}-\mathrm{CeO}_{2} \mathrm{NPs}$ film and preferentially into polymer matrix for PPy-NaPSS- $\mathrm{CeO}_{2}$ NPs film, as was concluded from electrochemical deposition and SEM analyses.

The increasing in atomic\% for $\mathrm{C}$ and $\mathrm{N}$ elements (provided by polypyrrole) for $\mathrm{PPy}-\mathrm{CeO}_{2} \mathrm{NPs}$ comparing with $\mathrm{PPy}$ indicates a higher amount of polypyrrole. However, the corresponding electrical charge used for polymerization was diminished (from $0.24 \mathrm{C} / \mathrm{cm}^{2}$ to $0.20 \mathrm{C} / \mathrm{cm}^{2}$, Figure 5), suggesting a negative influence of $\mathrm{CeO}_{2} \mathrm{NPs}$ over PPy doping process. In the presence of $\mathrm{NaPSS}$ and $\mathrm{CeO}_{2} \mathrm{NPs}$ (PPyNaPSS- $\mathrm{CeO}_{2}$ NPs) the amount of PPy (suggested by an increasing in atomic\% of $\mathrm{C}$ and $\mathrm{N}$ ) sustains the presumption mentioned in Section 3.2, according to which the thickness of the polymer film obtained in the presence of surfactant is higher.

3.3.2. Surface Wettability. The surface wettability is an important feature for many applications that implies the surface interaction with different biological entities such as bacteria or cells.

The contact angle measurements of the studied surfaces are presented in Table 2.

PPy film has a low hydrophobic behaviour. The presence of $\mathrm{CeO}_{2} \mathrm{NPs}$ on the polymeric film (PPy-CeO $\mathrm{CPs}_{2}$ ) leads to a decrease of the contact angle from $86.61^{\circ}$ to $78.64^{\circ}$. 


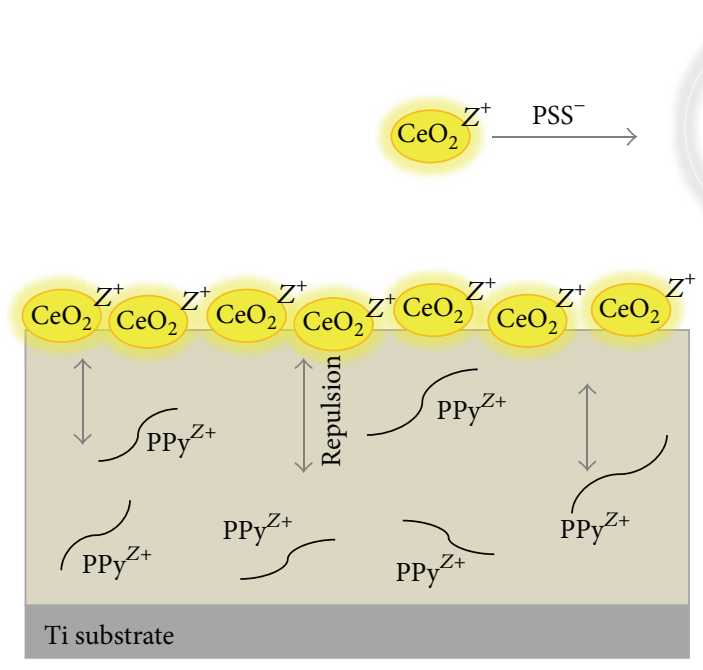

(a)
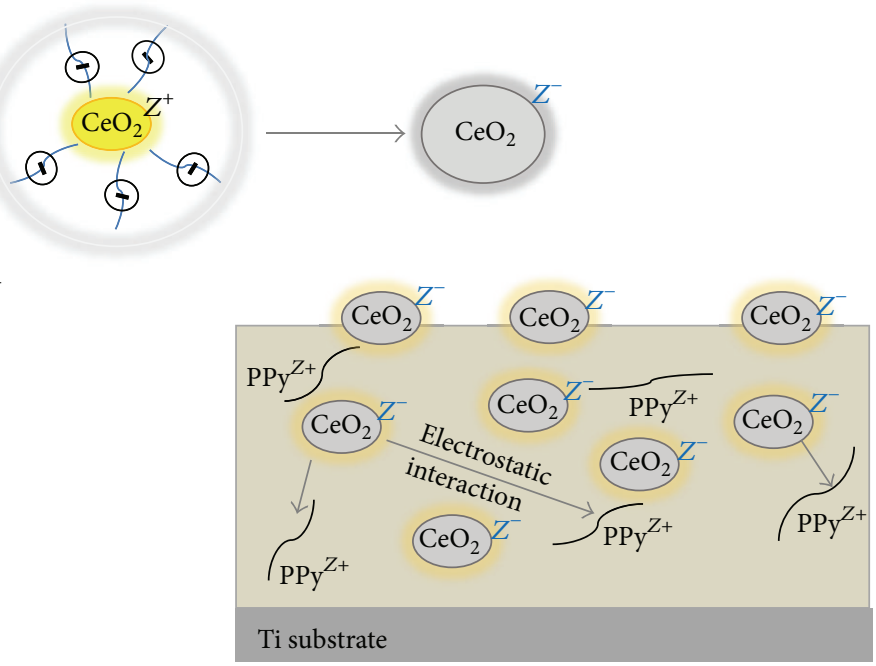

(b)

FIGURE 6: Electrostatic repulsions between positive cerium oxide and $\mathrm{PPy}^{+}(\mathrm{a})$; electrostatic interactions between negatively charged $\mathrm{CeO}_{2}$ nanoparticles (in the presence of NaPSS) and cationic $\mathrm{PPy}^{+}$matrix (b).

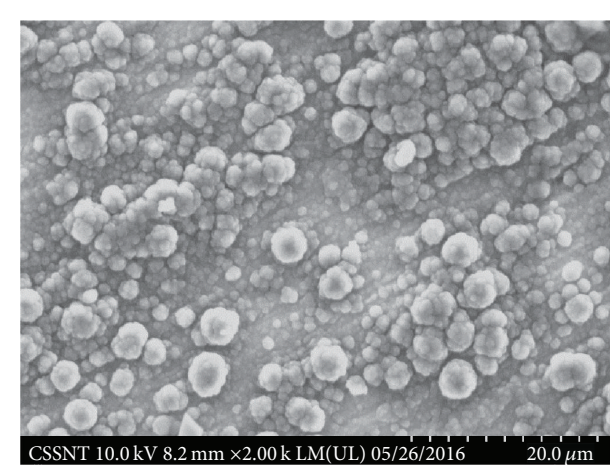

(a)

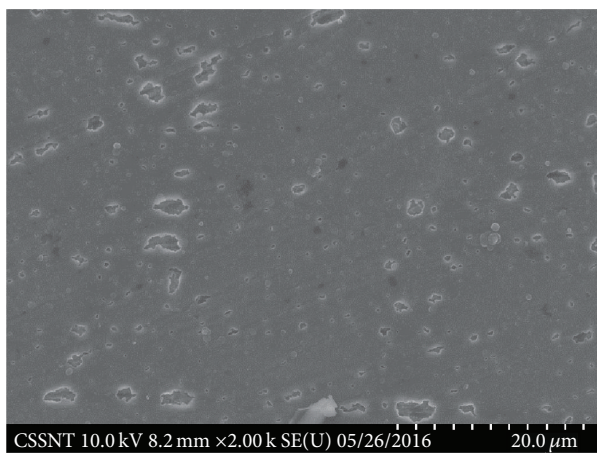

(c)

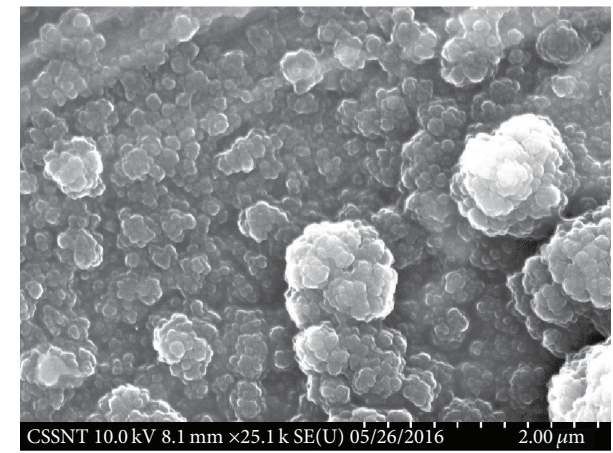

(b)

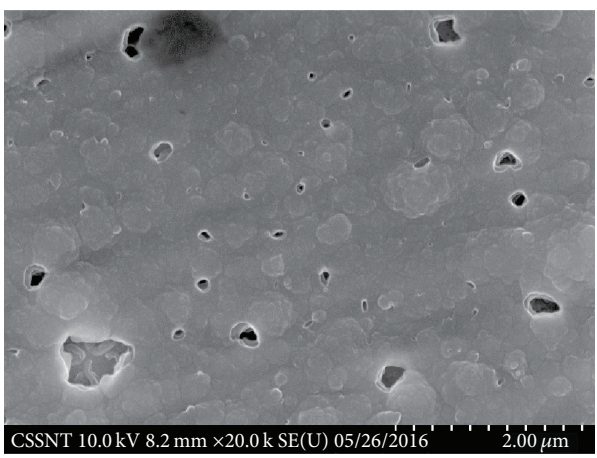

(d)

Figure 7: SEM images for PPy-CeO $\mathrm{CPs}_{2}$ ((a) and (b)) and PPy-NaPSS-CeO 2 NPs ((c) and (d)) nanocomposite films, electrodeposited from electrolytic aqueous solution containing pyrrole $\left(0.4 \mathrm{~mol} \cdot \mathrm{dm}^{-3}\right), \mathrm{CeO}_{2} \mathrm{NPs}\left(40 \mu \mathrm{g} \cdot \mathrm{mL}^{-1}\right)$, and $\mathrm{NaPSS}\left(0.1 \mathrm{~mol} \cdot \mathrm{dm}^{-3}\right)$.

However, the hydrophilic property of polymeric film was increased when the polymerization was performed in the presence of NaPSS surfactant. The contact angles for films in which NaPSS is present (Ti/PPy-NaPSS and Ti/PPy-NaPSS$\left.\mathrm{CeO}_{2} \mathrm{NPs}\right)$ are very close $\left(52.15^{\circ}\right.$ and $\left.53.88^{\circ}\right)$. This can be explained by the less influence of $\mathrm{CeO}_{2} \mathrm{NPs}$ on the wettability of the polymer film due to its embedding in the polymer matrix. Moreover, the effect of $\mathrm{CeO}_{2} \mathrm{NPs}$ bonded at the surface upon wettability is insignificant due to adsorption of NaPSS molecules on ceria nanoparticles. 


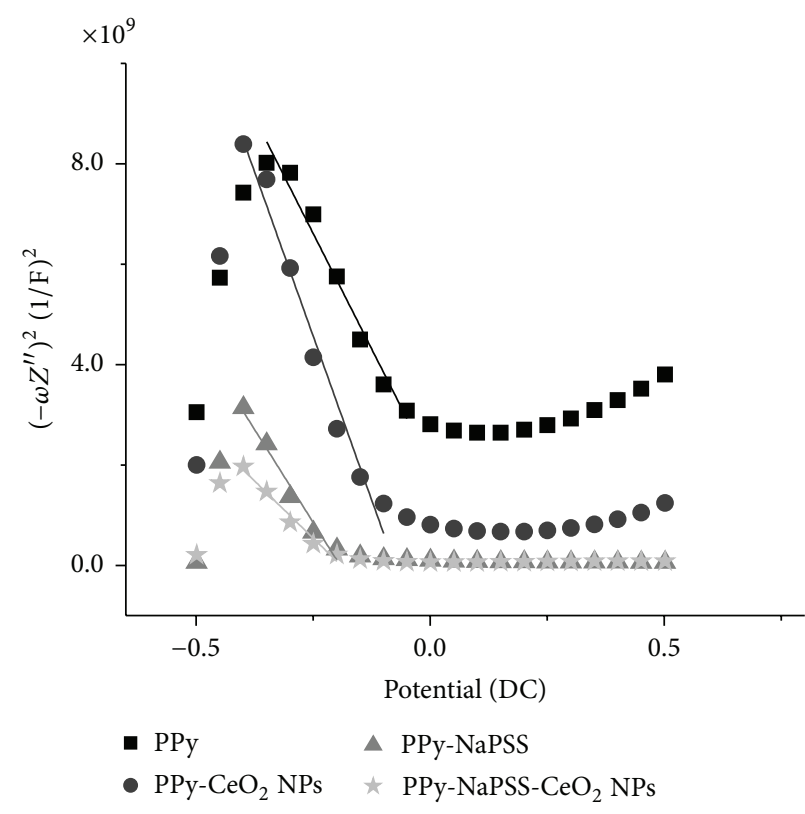

(a)

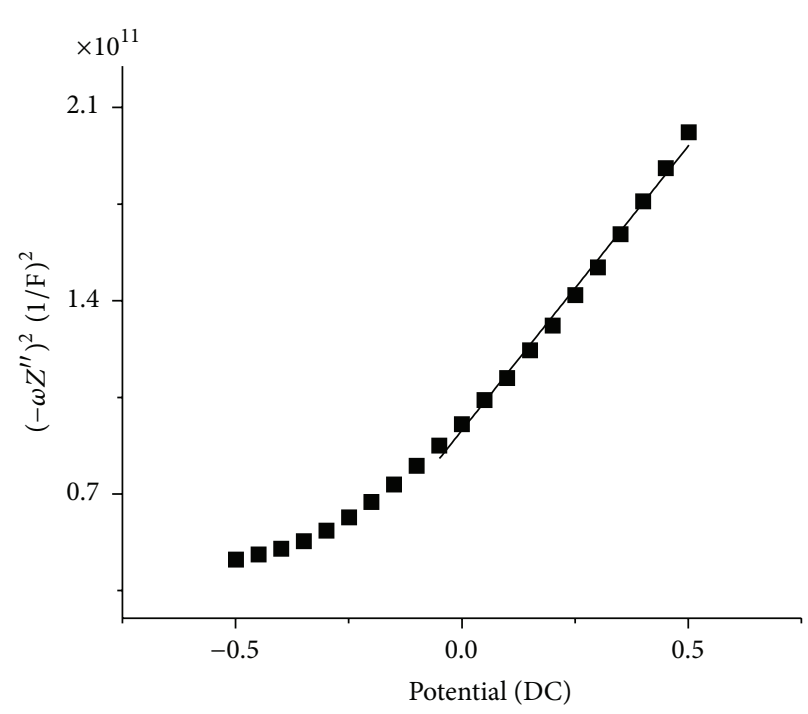

- $\mathrm{Ti}$

— Linear fit of $\mathrm{Ti}$

FIGURE 8: Mott-Schottky diagrams for (a) Ti/PPy films and (b) uncoated titanium.

TABLE 2: The contact angle measurements and standard deviations for PPy-nanocomposite films.

\begin{tabular}{|c|c|c|}
\hline Coating film & Contact angle, degrees & SD \\
\hline $\mathrm{Ti} / \mathrm{PPy}$ & 86.61 & \pm 2.29 \\
\hline Ti/PPy-NaPSS & 52.15 & \pm 2.53 \\
\hline $\mathrm{Ti} / \mathrm{PPy}-\mathrm{CeO}_{2} \mathrm{NPs}$ & 78.64 & \pm 1.88 \\
\hline Ti/PPy-NaPSS-CeO ${ }_{2}$ NPs & 53.88 & \pm 1.33 \\
\hline
\end{tabular}

\subsection{Electrochemical Characterization of PPy-Nanocomposite Films in Buffer Solution}

3.4.1. Mott-Schottky Analysis. In order to emphasize the changes in polymer films during $\mathrm{CeO}_{2}$ and/or surfactant embedding in the structure of PPy, the characterizations were supplemented with Mott-Schottky analysis. This technique based on capacitance versus potential measurements is a common in situ method for investigation of polymeric films semiconductor properties. Figure 8 presents the experimental data and the fit of linear domains of Mott-Schottky diagrams for all anodized samples. A positive slope can be observed for uncoated titanium, typical for $n$-type semiconductor, and negative slopes for polypyrrole coated titanium, typical for $p$-type semiconductor.

The flat band potential $\left(E_{\mathrm{fb}}\right)$ and charge carrier density $\left(N_{d}\right)$ data calculated from Mott-Schottky diagrams show significant changes in the semiconductor properties of the polypyrrole films during $\mathrm{CeO}_{2}$ NPs incorporation, Table 3 .

After insertion of $\mathrm{CeO}_{2}$ in/onto PPy film, $E_{\mathrm{fb}}$ is shifted in negative direction with about $180 \mathrm{mV}$, confirming that $\mathrm{CeO}_{2}$ NPs are positively charged in acid aqueous polymerization solution. $N_{d}$ of PPy film decreases in the presence of $\mathrm{CeO}_{2}$
NPs from $7.63 \cdot 10^{18} \mathrm{~m}^{-3}$ to $5.39 \cdot 10^{18} \mathrm{~m}^{-3}$, sustaining the negative influence of ceria nanoparticles over PPy doping, highlighted by EDX analysis and electrochemical polymerization process.

$\mathrm{CeO}_{2}$ nanoparticles insertion performed in the presence of surfactant has not caused a shifting of $E_{\mathrm{fb}},-192 \mathrm{mV}$ for PPy-NaPSS, and $-191 \mathrm{mV}$ for PPy-NaPSS-CeO ${ }_{2}$. Moreover, the presence of anionic surfactant in the polypyrrole film is clearly evidenced by a shifting of $E_{\mathrm{fb}}$ in cathodic direction, with about $300 \mathrm{mV}$ and an increase of the charge carrier density of PPy film from $7.63 \cdot 10^{18} \mathrm{~m}^{-3}$ to $9.52 \cdot 10^{18} \mathrm{~m}^{-3}$. Furthermore, the increase of $E_{\mathrm{fb}}$ of PPy-NaPSS film after $\mathrm{CeO}_{2} \mathrm{NPs}$ insertion, from $9.52 \cdot 10^{18} \mathrm{~m}^{-3}$ to $1.548 \cdot 10^{19} \mathrm{~m}^{-3}$, shows that, in this situation, the negative effect of ceria nanoparticles on the doping process is not observed in the presence of surfactant. Thus, the influence of surfactant is prevalent on the doping process due to the presence of the adsorbed surfactant cage around ceria nanoparticles.

3.4.2. Electrochemical Impedance Spectroscopy. Electrochemical impedance spectroscopy performed at open circuit potential in buffer solution was discussed in terms of Nyquist plots (Figure 9).

The equivalent electric circuits used to fit the EIS data with Nova software are represented in Figure 10. For PPy and $\mathrm{PPy}-\mathrm{CeO}_{2}$ NPs films, a two-time constant circuit was used (Figure 10(a)), where $R_{\mathrm{s}}$ is solution resistance, $R_{\mathrm{ct} 1}$ is the resistance responsible for the ion transfer through polymeric film, connected in parallel with a constant phase element $\mathrm{CPE}_{1}$, and $n$ is the phase change values. $R_{\mathrm{ct} 2}$ is the resistance responsible for the electron transfer and $\mathrm{CPE}_{2}$ is the second constant phase element for electric double layer. Another constant phase element $\mathrm{CPE}_{3}$ was introduced for 
TABLE 3: Charge carrier density $\left(N_{d}\right)$ and flat band potential $\left(E_{\mathrm{fb}}\right)$ from Mott-Schottky diagrams.

\begin{tabular}{lcccc}
\hline Electrical parameters & $\mathrm{PPy}$ & $\mathrm{PPy}_{-\mathrm{CeO}} \mathrm{NPs}_{2}$ & $\mathrm{PPy}-\mathrm{NaPSS}$ & $\mathrm{PPy}_{\mathrm{NaPSS}-\mathrm{CeO}} \mathrm{NPs}$ \\
\hline$E_{\mathrm{fb}}(\mathrm{V})$ & 0.108 & -0.075 & -0.192 & -0.191 \\
$N_{d}\left(\mathrm{~m}^{-3}\right)$ & $7.630 \cdot 10^{18}$ & $5.395 \cdot 10^{18}$ & $0.952 \cdot 10^{19}$ & $1.548 \cdot 10^{19}$ \\
\hline
\end{tabular}

TABLE 4: Electric parameters from fitting experimental EIS data.

\begin{tabular}{|c|c|c|c|c|}
\hline \multirow{2}{*}{ Parameters } & \multicolumn{4}{|c|}{ Polymeric-nanocomposite films } \\
\hline & PPy & $\mathrm{PPy}-\mathrm{CeO}_{2} \mathrm{NPs}$ & PPy-NaPSS & PPy-NaPSS-CeO ${ }_{2} \mathrm{NPs}$ \\
\hline$R_{\mathrm{s}}\left(\Omega \mathrm{cm}^{2}\right)$ & 119 & 25.1 & 117 & 160 \\
\hline$R_{\mathrm{ctl}}\left(\Omega \mathrm{cm}^{2}\right)$ & 83.2 & 51.5 & $6.810 \cdot 10^{+3}$ & $4.370 \cdot 10^{+3}$ \\
\hline $\mathrm{CPE}_{1}\left(\Omega^{-1} \mathrm{~cm}^{-2} \mathrm{~s}^{n}\right)$ & $3.96 \cdot 10^{-3}$ & $7.99 \cdot 10^{-6}$ & $1.860 \cdot 10^{-3}$ & $1.370 \cdot 10^{-3}$ \\
\hline$n_{1}$ & 0.773 & 0.360 & 0.868 & 0.785 \\
\hline$R_{\mathrm{ct} 2}\left(\Omega \mathrm{cm}^{2}\right)$ & 56 & 117 & - & - \\
\hline $\mathrm{CPE}_{2}\left(\Omega^{-1} \mathrm{~cm}^{-2} \mathrm{~s}^{n}\right)$ & $9.750 \cdot 10^{-6}$ & $4.050 \cdot 10^{-3}$ & - & - \\
\hline$n_{2}$ & 0.342 & 0.790 & - & - \\
\hline $\mathrm{CPE}_{3}\left(\Omega^{-1} \mathrm{~cm}^{-2} \mathrm{~s}^{n}\right)$ & $5.570 \cdot 10^{-3}$ & $5.12 \cdot 10^{-3}$ & - & - \\
\hline$n_{3}$ & 0.963 & 0.976 & - & - \\
\hline
\end{tabular}

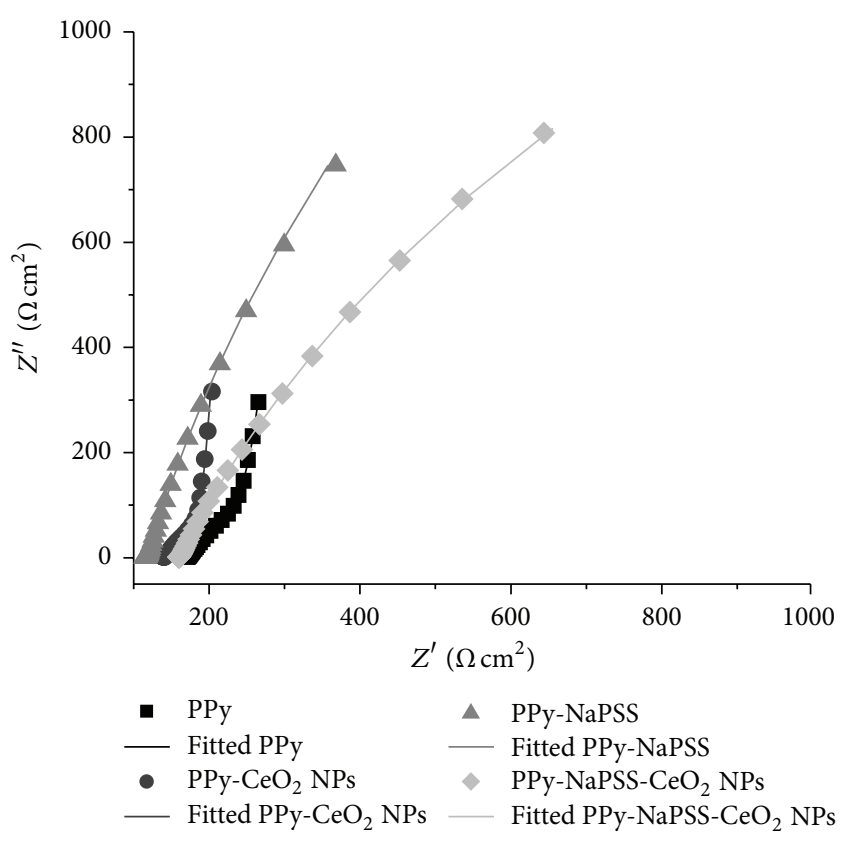

FIGURE 9: Nyquist spectra for PPy-nanocomposite films/Ti in buffer solution.

lower frequency corresponding to capacitive behaviour of these films [40].

On the other hand, for more compact PPy-nanocomposite films, PPy-NaPSS and PPy-NaPSS-CeO 2 NPs, the EIS data were fitted with an equivalent electric circuit with onetime constant (Figure 10(b)), where $R_{\mathrm{s}}$ is solution resistance, $R_{\mathrm{ct} 1}$ is charge transfer resistance, and $\mathrm{CPE}_{1}$ is constant phase element.
Electric parameters obtained from fitted experimental EIS data with proposed equivalent circuits are presented in Table 4 .

The presence of the cationic oxide $\mathrm{CeO}_{2}$ NPs in polymerization solution is reflected by the values of the electron transfer resistance $\left(R_{\mathrm{ct} 2}\right)$. For $\mathrm{PPy}-\mathrm{CeO}_{2} \mathrm{NPs}$ film, $R_{\mathrm{ct} 2}$ is higher $\left(117 \Omega \mathrm{cm}^{2}\right)$ comparing with that of PPy film $\left(56 \Omega \mathrm{cm}^{2}\right)$. This observation is in accordance with charge carrier density $\left(N_{d}\right)$ values obtained from Mott-Schottky analysis which are superior for PPy film than PPy-CeO ${ }_{2} \mathrm{NPs}$. However, $R_{\mathrm{ct} 1}$, associated with ion transfer resistance, decreases when $\mathrm{CeO}_{2}$ NPs were added in the polymeric film, probably due to a presumed increase in ionic film permeability, as was reported in literature [37].

Also, in NaPSS presence the charge transfer resistance increased with one order of magnitude compared to those of polymeric films without surfactant, which could suggests that the resulted PPy-NaPSS films are more compact and stable. On the other hand, $N_{d}$ values obtained from MottSchottky analysis indicated an increase in PPy doping process in the presence of surfactant. Thus, although PPy film which resulted in the presence of surfactant should be more conductive, the resistance values are higher. This behaviour can be explained on the base of parallel adsorption processes of PSS $^{-}$on titanium surface at the beginning of anodic polymerization that leads to a possible partial passivation of the substrate.

The embedding of $\mathrm{CeO}_{2}$ NPs into PPy-NaPSS-CeO $\mathrm{CPs}_{2}$ film shows a decreasing of charge transfer resistance, from $6.81 \mathrm{k} \Omega \cdot \mathrm{cm}^{2}$ to $4.37 \mathrm{k} \Omega \cdot \mathrm{cm}^{2}$, probably due to the similar processes presented above. $n$ value of constant phase element is also slightly reduced from 0.86 to 0.78 , sustaining a reduction in capacitive behaviour of the polypyrrole film, due to ionic permeation. 


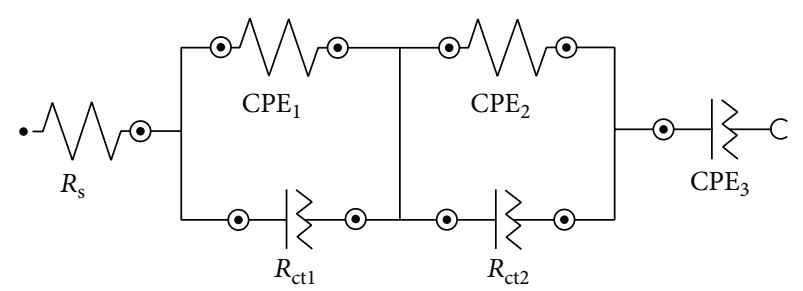

(a)

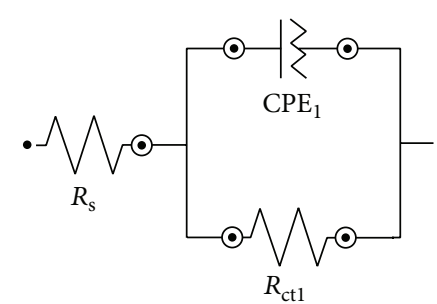

(b)

Figure 10: The equivalent circuits used to fit EIS data for (a) PPy and PPy-CeO $\mathrm{CPs}_{2}$ films and (b) PPy-NaPSS and PPy-NaPSS-CeO 2 NPs films.

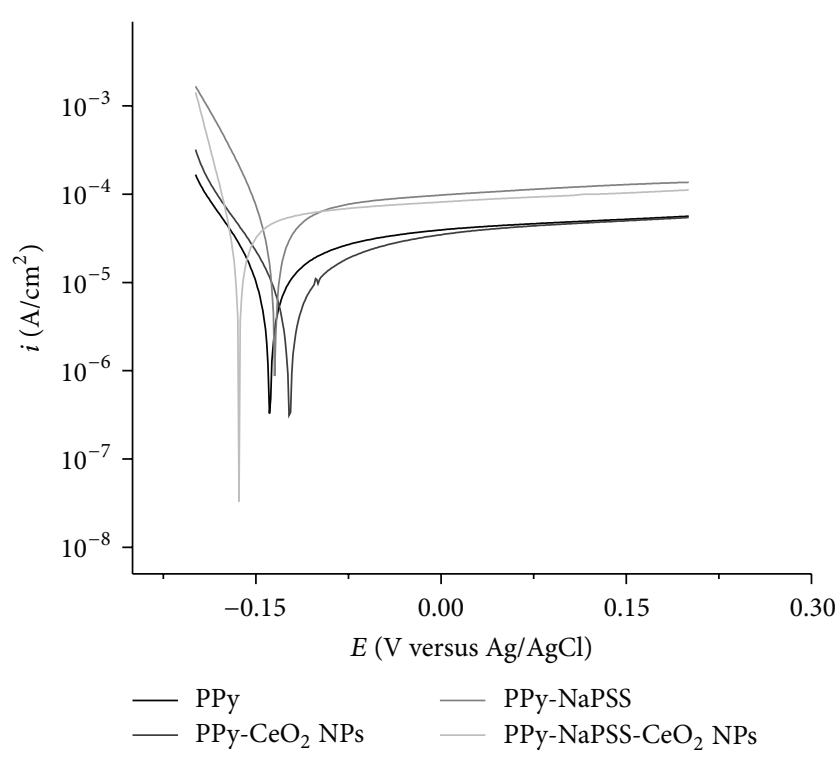

Figure 11: Tafel diagrams for PPy-nanocomposite films on Ti in buffer solution.

3.4.3. Tafel Diagrams. Figure 11 shows the set of polarization curves recorded for PPy-nanocomposite films in buffer solution.

The electrochemical parameters computed with Nova software are presented in Table 5.

The polarization resistance $\left(R_{\mathrm{p}}\right)$ values obtained from Tafel analysis performed in d.c. current depend on many surface features, such as film conductivity associated with the doping process, film permeability, substrate passivation connected with surfactant adsorption, and titanium oxide formation.

$R_{\mathrm{p}}$ values from Tafel plots for PPy and $\mathrm{PPy}-\mathrm{CeO}_{2}$ NPs films are different than the $R_{\mathrm{ct}}$ values obtained from EIS (performed in a.c. current) with about one order of magnitude. These different results obtained by different techniques could be due to the effect of electrical imposed perturbations on the coating properties. The EIS analysis is performed at free potential with small perturbation amplitude of $10 \mathrm{mV}$ and the film properties are not importantly affected. On the contrary,
Tafel analysis is performed in $\pm 200 \mathrm{mV}$ perturbation, stimulating reduction/oxidation processes (undoping/doping) of the polypyrrole film which involve insertion/repulsion of anions and cations into/through the polymeric film, as represented in (3) and (4) [40]. One has

$$
\begin{aligned}
& \mathrm{PPy}+n \mathrm{~A}^{-} \stackrel{\text { oxidation }}{\longrightarrow}\left[(\mathrm{PPy})^{n+}\left(\mathrm{A}^{-}\right)_{n}\right]+n \mathrm{e}^{-} \\
& {\left[(\mathrm{PPy})^{n+}\left(\mathrm{A}^{-}\right)_{n}\right]+n \mathrm{C}^{+}+n \mathrm{e}^{-}} \\
& \stackrel{\text { reduction }}{\longrightarrow}\left[(\mathrm{PPy})\left(\mathrm{A}^{-}\right)_{n}\left(\mathrm{C}^{+}\right)_{n}\right]
\end{aligned}
$$

These insertion/repulsion processes lead to increase of PPy film permeability and the electrolyte can reach more easily to the surface of titanium substrate, promoting the resistive $\mathrm{TiO}_{2}$ oxide layer formation between PPy film and Ti. For PPy-NaPSS and PPy-NaPSS-CeO ${ }_{2}$ NPs films, $R_{p}$ values obtained from Tafel plots are in a good correlation with those obtained from EIS data, sustaining once again the stability and the less permeability of PPy-NaPSS films conferred by the presence of surfactant. The PSS ${ }^{-}$mobility during potential perturbation is reduced comparing with oxalate anion. Thus, the film remains more compact avoiding the electrolyte insertion.

3.5. Antibacterial Activity. In Figure 12 the influence of $\mathrm{CeO}_{2}$ NPs bonded in PPy matrix on antibacterial activity of polymeric film was represented.

The presence of uniform spreading $\mathrm{CeO}_{2}$ NPs agglomerates onto polymeric matrix $\left(\mathrm{PPy}-\mathrm{CeO}_{2}\right)$ improves the antibacterial activity of the polymeric film, being in accordance with the literature data which specified that the nanoparticles of $\mathrm{CeO}_{2}$ have a good antibacterial effect on Escherichia coli [44].

PPy-NaPSS- $\mathrm{CeO}_{2}$ NPs film has a slightly lower antibacterial activity than $\mathrm{PPy}_{-} \mathrm{CeO}_{2} \mathrm{NPs}$ film. The different doping process in the presence of NaPSS and the better embedding of negatively charged $\mathrm{CeO}_{2} \mathrm{NPs}$ lead to a small amount of $\mathrm{CeO}_{2}$ NPs on the polymer surface.

Thus, the role of the surfactant becomes determinant during polymerization and the interaction between $\mathrm{CeO}_{2}$ NPs and PPy films has a strong influence on antibacterial activity. If the nanoparticles are on the polymer surface, the antibacterial effect is improved but if nanoparticles are 
TABLE 5: Electrochemical parameters from Tafel diagrams.

\begin{tabular}{lcccc}
\hline Electrochemical parameters & $\mathrm{PPy}$ & $\mathrm{PPy}_{-\mathrm{CeO}} \mathrm{NPs}_{2}$ & $\mathrm{PPy}_{\mathrm{NaPSS}}$ & $\mathrm{PPy}-\mathrm{NaPSS}-\mathrm{CeO} \mathrm{NPs}_{2}$ \\
\hline$E_{\text {cor }}(\mathrm{mV})$ & -138 & -125 & -135 & -167 \\
$i_{\text {cor }}\left(\mu \mathrm{A} / \mathrm{cm}^{2}\right)$ & 19.390 & 12.321 & 53.300 & 22.268 \\
$v_{\text {cor }}(\mathrm{mm} /$ year $)$ & 0.169 & 0.107 & 0.464 & 0.194 \\
$R_{\mathrm{p}}(\mathrm{k} \Omega)$ & 4.617 & 6.206 & 1.083 & 1.060 \\
\hline
\end{tabular}

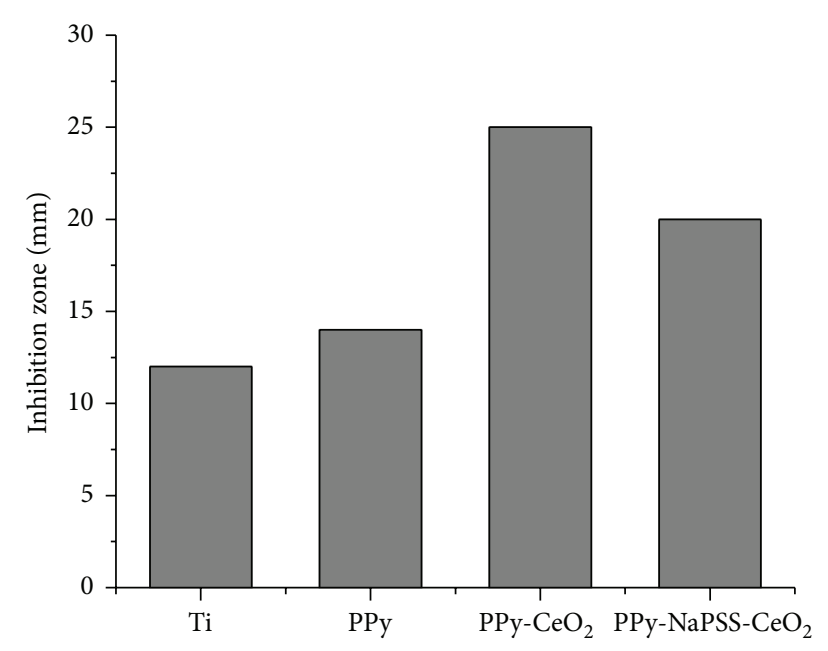

FIgURE 12: Antibacterial activity of PPy-nanocomposite films on Escherichia coli.

preponderantly embedded into PPy film, the antibacterial activity is slightly decreased.

The results obtained from antibacterial activity of PPynanocomposite films on Escherichia coli confirm and sustain the observations arising out from the surface and electrochemical analysis regarding $\mathrm{CeO}_{2} \mathrm{NPs}$ bonding into/onto polymeric matrix.

\section{Conclusions}

$\mathrm{CeO}_{2}$ nanoparticles with dimension of tens nanometers were synthesized by a coprecipitation method. The influence of NaPSS surfactant on the embedded $\mathrm{CeO}_{2} \mathrm{NPs}$ in polypyrrole films was investigated. $\mathrm{CeO}_{2}$ nanoparticles with dimension of tens nanometers were synthesized by a coprecipitation method and embedded in polypyrrole films in presence of NaPSS surfactant.

From surface and electrochemical characterization it was highlighted that NaPSS surfactant and $\mathrm{CeO}_{2}$ NPs play an important role in PPy doping process. NaPSS presence improves $\mathrm{CeO}_{2}$ NPs embedding into PPy matrix. The adsorption of PSS $^{-}$anions on the nanoparticles surface leads to negatively charged $\mathrm{CeO}_{2}$ NPs and improves the electrostatic interactions with cationic $\mathrm{PPy}^{+}$matrix (doping).

In the presence of surfactant $\mathrm{CeO}_{2}$ NPs are preferentially embedded in the polymeric film while, without surfactant, the ceria nanoparticles are quasiuniformly spread as agglomerates onto polymeric films.
This different distribution of ceria nanoparticles into/ onto polypyrrole influences the film stability and even its possible applications.

\section{Competing Interests}

The authors declare that they have no competing interests.

\section{Acknowledgments}

This work was supported by a project of CNCS-UEFISCDI, PN2-253/2014-NANOCOAT. The authors wish to thank Ms. Cristina Nicolescu for XRD analysis and Ms. Camelia Ungureanu for antibacterial activity analysis.

\section{References}

[1] J. L. Chen, C. Chen, Z. Y. Chen, J. Y. Chen, Q. L. Li, and N. Huang, "Collagen/heparin coating on titanium surface improves the biocompatibility of titanium applied as a bloodcontacting biomaterial," Journal of Biomedical Materials Research Part A, vol. 95, no. 2, pp. 341-349, 2010.

[2] M. Geetha, A. K. Singh, R. Asokamani, and A. K. Gogia, “Ti based biomaterials, the ultimate choice for orthopaedic implants-a review," Progress in Materials Science, vol. 54, no. 3, pp. 397-425, 2009.

[3] W. Ma, S.-H. Wang, G.-F. Wu et al., "Preparation and in vitro biocompatibility of hybrid oxide layer on titanium surface," Surface and Coatings Technology, vol. 205, no. 6, pp. 1736-1742, 2010.

[4] S. Mei, H. Wang, W. Wang et al., "Antibacterial effects and biocompatibility of titanium surfaces with graded silver incorporation in titania nanotubes," Biomaterials, vol. 35, no. 14, pp. 4255-4265, 2014.

[5] Y.-H. Lee, G. Bhattarai, S. Aryal et al., "Modified titanium surface with gelatin nano gold composite increases osteoblast cell biocompatibility," Applied Surface Science, vol. 256, no. 20, pp. 5882-5887, 2010.

[6] K. Gulati, S. Ramakrishnan, M. S. Aw, G. J. Atkins, D. M. Findlay, and D. Losic, "Biocompatible polymer coating of titania nanotube arrays for improved drug elution and osteoblast adhesion," Acta Biomaterialia, vol. 8, no. 1, pp. 449-456, 2012.

[7] S. K. Mishra and S. Kannan, "Development, mechanical evaluation and surface characteristics of chitosan/polyvinyl alcohol based polymer composite coatings on titanium metal," Journal of the Mechanical Behavior of Biomedical Materials, vol. 40, pp. 314-324, 2014. 
[8] S. K. Mishra, J. M. F. Ferreira, and S. Kannan, "Mechanically stable antimicrobial chitosan-PVA-silver nanocomposite coatings deposited on titanium implants," Carbohydrate Polymers, vol. 121, pp. 37-48, 2015.

[9] K. Ishihara and J. Chol, "Biocompatible polymer assembly on metal surfaces," Metals for Biomedical Devices, pp. 283-302, 2010.

[10] H. Chen, L. Yuan, W. Song, Z. Wu, and D. Li, "Biocompatible polymer materials: role of protein-surface interactions," Progress in Polymer Science, vol. 33, no. 11, pp. 1059-1087, 2008.

[11] G. Hélary, F. Noirclère, J. Mayingi, and V. Migonney, "A new approach to graft bioactive polymer on titanium implants: improvement of MG 63 cell differentiation onto this coating," Acta Biomaterialia, vol. 5, no. 1, pp. 124-133, 2009.

[12] G. Tan, L. Zhou, C. Ning et al., "Biomimetically-mineralized composite coatings on titanium functionalized with gelatin methacrylate hydrogels," Applied Surface Science, vol. 279, pp. 293-299, 2013.

[13] A. de Leon and R. C. Advincula, "Conducting polymers with superhydrophobic effects as anticorrosion coating," in Intelligent Coatings for Corrosion Control, A. Tiwari, L. Hihara, and J. Rawlins, Eds., pp. 409-430, 2015.

[14] P. Zarras and J. D. Stenger-Smith, "Electro-active polymer (EAP) coatings for corrosion protection of metals," in Handbook of Smart Coatings for Materials Protection, A. S. H. Makhlouf, Ed., pp. 328-369, Woodhead, Cambridge, UK, 2014.

[15] D. D. Ateh, P. Vadgama, and H. A. Navsaria, "Culture of human keratinocytes on polypyrrole-based conducting polymers," Tissue Engineering, vol. 12, no. 4, pp. 645-655, 2006.

[16] Y. Li, K. G. Neoh, L. Cen, and E. T. Kang, "Porous and electrically conductive polypyrrole- Poly (vinyl alcohol) composite and its applications as a biomaterial," Langmuir, vol. 21, no. 23, pp. 10702-10709, 2005.

[17] G. M. Spinks, V. Mottaghitalab, M. Bahrami-Samani, P. G. Whitten, and G. G. Wallace, "Carbon-nanotube-reinforced polyaniline fibers for high-strength artificial muscles," Advanced Materials, vol. 18, no. 5, pp. 637-640, 2006.

[18] E. De Giglio, M. R. Guascito, L. Sabbatini, and G. Zambonin, "Electropolymerization of pyrrole on titanium substrates for the future development of new biocompatible surfaces," Biomaterials, vol. 22, no. 19, pp. 2609-2616, 2001.

[19] K. Idla, O. Inganäs, and M. Strandberg, "Good adhesion between chemically oxidised titanium and electrochemically deposited polypyrrole," Electrochimica Acta, vol. 45, no. 13, pp. 2121-2130, 2000.

[20] X. Wang, X. Gu, C. Yuan et al., "Evaluation of biocompatibility of polypyrrole in vitro and in vivo," Journal of Biomedical Materials Research-Part A, vol. 68, no. 3, pp. 411-422, 2004.

[21] S. T. Earley, D. P. Dowling, J. P. Lowry, and C. B. Breslin, "Formation of adherent polypyrrole coatings on $\mathrm{Ti}$ and $\mathrm{Ti}-6 \mathrm{Al}-$ 4V alloy," Synthetic Metals, vol. 148, no. 2, pp. 111-118, 2005.

[22] Z. Weiss, D. Mandler, G. Shustak, and A. J. Domb, "Pyrrole derivatives for electrochemical coating of metallic medical devices," Journal of Polymer Science Part A: Polymer Chemistry, vol. 42, no. 7, pp. 1658-1667, 2004.

[23] M. Mîndroiu, C. Ungureanu, R. Ion, and C. Pîrvu, "The effect of deposition electrolyte on polypyrrole surface interaction with biological environment," Applied Surface Science, vol. 276, pp. 401-410, 2013.

[24] S. M. Dizaj, F. Lotfipour, M. Barzegar-Jalali, M. H. Zarrintan, and K. Adibkia, "Antimicrobial activity of the metals and metal oxide nanoparticles," Materials Science and Engineering C, vol. 44, pp. 278-284, 2014.

[25] R. Gokulakrishnan, S. Ravikumar, and J. A. Raj, "In vitro antibacterial potential of metal oxide nanoparticles against antibiotic resistant bacterial pathogens," Asian Pacific Journal of Tropical Disease, vol. 2, no. 5, pp. 411-413, 2012.

[26] M. Moritz and M. Geszke-Moritz, "The newest achievements in synthesis, immobilization and practical applications of antibacterial nanoparticles," Chemical Engineering Journal, vol. 228, pp. 596-613, 2013.

[27] A. S. Karakoti, N. A. Monteiro-Riviere, R. Aggarwal et al., "Nanoceria as antioxidant: synthesis and biomedical applications," The Journal of The Minerals, Metals \& Materials Society, vol. 60 , no. 3, pp. 33-37, 2008.

[28] V. Shah, S. Shah, H. Shah et al., "Antibacterial activity of polymer coated cerium oxide nanoparticles," PLOS ONE, vol. 7, article e47827, 2012.

[29] C. H. Baker, "Harnessing cerium oxide nanoparticles to protect normal tissue from radiation damage," Translational Cancer Research, vol. 2, pp. 343-358, 2013.

[30] F. Liu, Y. Yuan, L. Li et al., "Synthesis of polypyrrole nanocomposites decorated with silver nanoparticles with electrocatalysis and antibacterial property," Composites Part B: Engineering, vol. 69, pp. 232-236, 2014.

[31] M. B. González, L. I. Brugnoni, M. E. Vela, and S. B. Saidman, "Silver deposition on polypyrrole films electrosynthesized in salicylate solutions," Electrochimica Acta, vol. 102, pp. 66-71, 2013.

[32] E. N. Zare, M. M. Lakouraj, and M. Mohseni, "Biodegradable polypyrrole/dextrin conductive nanocomposite: synthesis, characterization, antioxidant and antibacterial activity," Synthetic Metals, vol. 187, no. 1, pp. 9-16, 2014.

[33] M. Cabuk, Y. Alan, M. Yavuz, and H. I. Unal, "Synthesis, characterization and antimicrobial activity of biodegradable conducting polypyrrole-graft-chitosan copolymer," Applied Surface Science, vol. 318, pp. 168-175, 2014.

[34] C. Ungureanu, C. Pirvu, M. Mindroiu, and I. Demetrescu, "Antibacterial polymeric coating based on polypyrrole and polyethylene glycol on a new alloy TiAlZr," Progress in Organic Coatings, vol. 75, no. 4, pp. 349-355, 2012.

[35] C. Ungureanu, S. Popescu, G. Purcel et al., "Improved antibacterial behavior of titanium surface with torularhodin-polypyrrole film," Materials Science and Engineering C, vol. 42, pp. 726-733, 2014.

[36] K.-Q. Liu, C.-X. Kuang, M.-Q. Zhong, Y.-Q. Shi, and F. Chen, "Synthesis, characterization and UV-shielding property of polystyrene-embedded $\mathrm{CeO}_{2}$ nanoparticles," Optical Materials, vol. 35, no. 12, pp. 2710-2715, 2013.

[37] C. Benmouhoub, J. Agrisuelas, N. Benbrahim et al., "Influence of the incorporation of $\mathrm{CeO}_{2}$ nanoparticles on the ion exchange behavior of dodecylsulfate doped polypyrrole films: Ac-electrogravimetry investigations," Electrochimica Acta, vol. 145, pp. 270-280, 2014.

[38] C. Pirvu, M. Mindroiu, S. Popescu, and I. Demetrescu, "Electrodeposition of polypyrrole/poly(Styrene Sulphonate) composite coatings on Ti6Al7Nb alloy," Molecular Crystals and Liquid Crystals, vol. 521, pp. 126-139, 2010.

[39] M. Mindroiu, R. Ion, C. Pirvu, and A. Cimpean, "Surfactantdependent macrophage response to polypyrrole-based coatings electrodeposited on $\mathrm{Ti}_{6} \mathrm{Al}_{7} \mathrm{Nb}$ alloy," Materials Science and Engineering C, vol. 33, no. 6, pp. 3353-3361, 2013. 
[40] C. Pirvu, C. C. Manole, A. B. Stoian, and I. Demetrescu, "Understanding of electrochemical and structural changes of polypyrrole/polyethylene glycol composite films in aqueous solution," Electrochimica Acta, vol. 56, no. 27, pp. 9893-9903, 2011.

[41] J. H. Jorgensen and J. D. Turnidge, Susceptibility Test Methods: Dilution and Disk Diffusion Methods, ASM Press, 2015.

[42] R. Bouldin, S. Ravichandran, A. Kokil et al., "Synthesis of polypyrrole with fewer structural defects using enzyme catalysis," Synthetic Metals, vol. 161, no. 15-16, pp. 1611-1617, 2011.

[43] A. Sehgal, Y. Lalatonne, J.-F. Berret, and M. Morvan, "Precipitation-redispersion of cerium oxide nanoparticles with poly (acrylic acid): toward stable dispersions," Langmuir, vol. 21, no. 20, pp. 9359-9364, 2005.

[44] Y. Kuang, X. He, Z. Zhang et al., "Comparison study on the antibacterial activity of nano-or bulk-cerium oxide," Journal of Nanoscience and Nanotechnology, vol. 11, no. 5, pp. 4103-4108, 2011. 

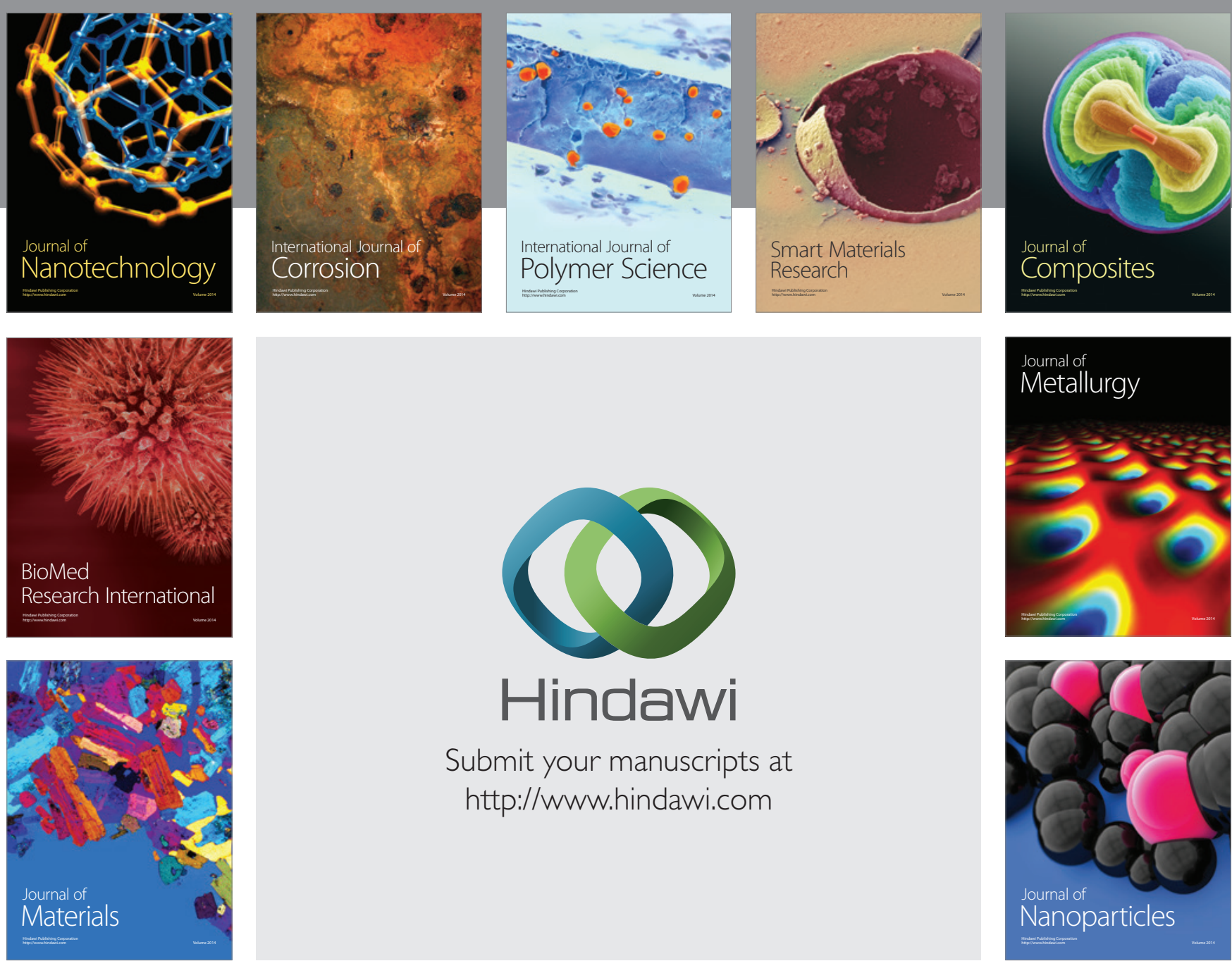

\section{Hindawi}

Submit your manuscripts at

http://www.hindawi.com

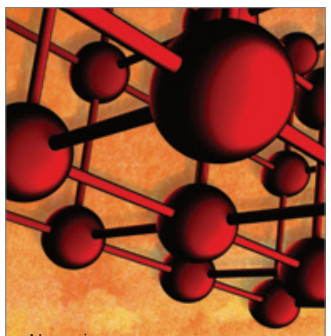

Materials Science and Engineering
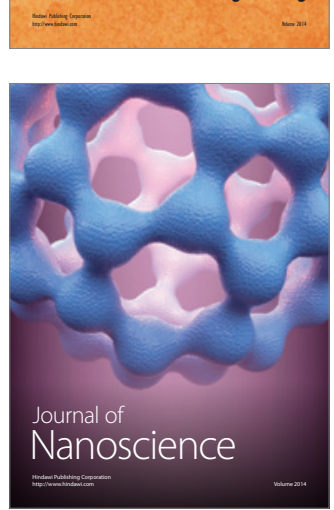
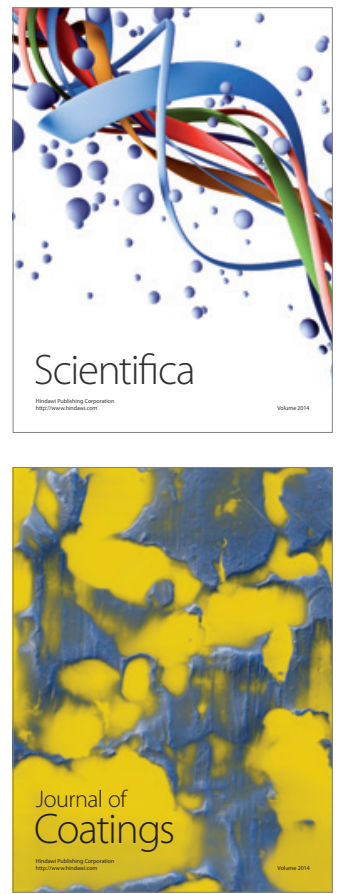
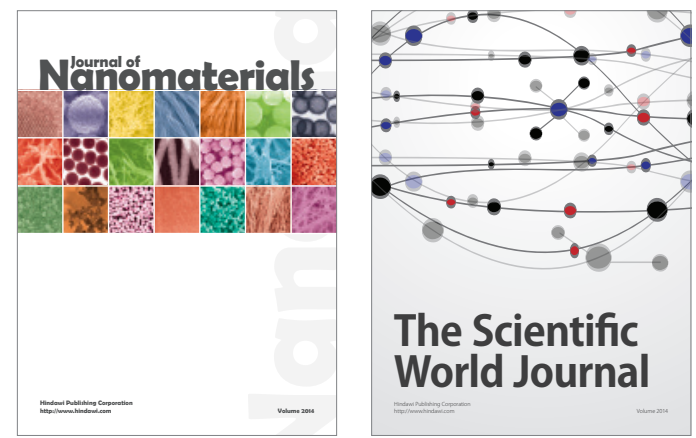

The Scientific World Journal
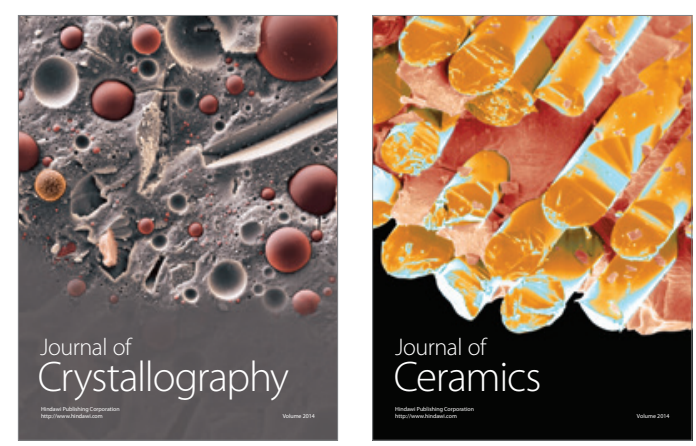
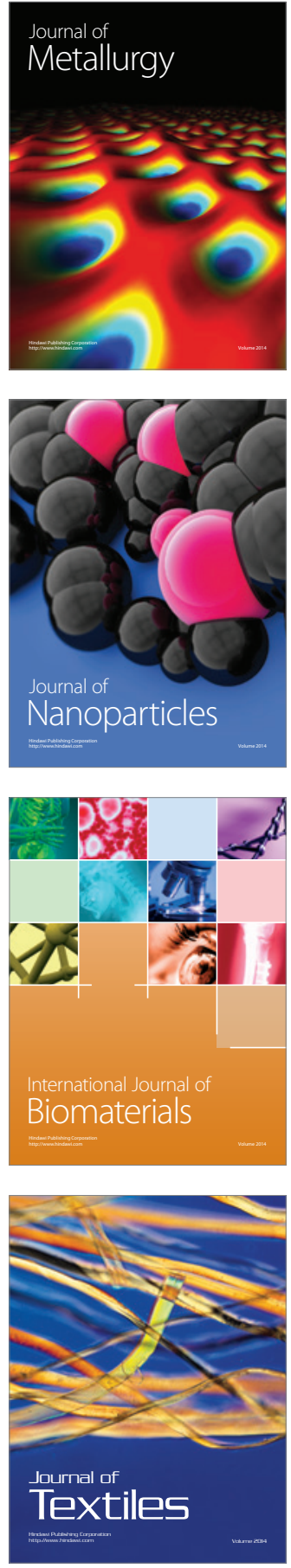